\title{
Divertida-mente: entrando no cinema pelo Projeto CineIFSC - Pipoca Educultural
}

\author{
Fun-mind: getting into the cinema by CineIFSC Project - Popcorn Educultural
}

\section{Divertida-mente: entrando en el cine por el Proyecto CineIFSC - Palomita Educativa}

\author{
ELIANE JURASKi CAMiLlO* \\ MARIA DOS ANJOS LOPES VIELLA**
}

\begin{abstract}
RESUMO
Este trabalho resultou do Projeto CineIFSC - Pipoca Educultural, que teve como objetivo potencializar a interpretação de textos e de mundos, via utilização do cinema com os alunos dos cursos técnicos em Fabricação Mecânica e Agroindústria do Instituto Federal de Santa Catarina (IFSC), Campus Xanxerê, no ano letivo de 2015. Assim, foi elaborado e colocado em prática o referido projeto, utilizando-se, para a coleta de dados, questionários aplicados aos alunos e professores antes da sua execução e registros dos debates realizados após a exibição dos filmes. Para fundamentar a análise, estabeleceu-se o diálogo com Catelli (2005), Duarte (2002), Napolitano (2013) e Roure (2011), entre outros. Os dados enfatizam um conjunto de habilidades e atitudes conquistadas pelos sujeitos que participaram do processo e apontam caminhos para um frutífero diálogo entre cinema e educação.
\end{abstract}

Palavras-chave: Leitura e interpretação. Cinema. Prática pedagógica.

\begin{abstract}
This paper resulted from CineIFSC Project - Popcorn Educultural aimed to enhance the interpretation of texts and worlds, via use of film text with students of technical courses in Mechanical and Manufacturing Agroindústria the Federal Institute of Santa Catarina-IFSC, Campus Xanxerê, in the academic year 2015. Thus, it was made and put into practice the said project using to collect data, questionnaires to students and teachers before the execution of the project and records of discussions after the screening of the movies. To support the analysis established the dialogue with Catelli (2005), Duarte (2002), Napolitano (2013), Roure (2011) among others. The data emphasize a set of skills and attitudes conquered by the subjects who participated in the process and shows the way for a fruitful dialogue between cinema and education.
\end{abstract}

Keywords: Reading and interpretation. Cinema. Pedagogical practice.

\section{RESUMEN}

Este trabajo resultó del Proyecto CineIFSC - Pipoca Educultural que tuvo como objetivo potenciar la interpretación de textos y de mundos, vía utilización del texto cinematográfico con los alumnos de los cursos técnicos en Fabricación Mecánica y Agroindustria del Instituto Federal de Santa CatarinaIFSC, Câmpus Xanxerê, en el año escolar de 2015. Así, fue elaborado y puesto en práctica el referido Proyecto utilizando para la recolección de datos, de cuestionarios aplicados a los alumnos y profesores antes de la ejecución del proyecto y de registros de los debates realizados después de la exhibición de las películas. Para fundamentar el análisis se estableció el diálogo con Catelli (2005), Duarte (2002), Napolitano (2013), Roure (2011) entre otros. Los datos enfatizan un conjunto de habilidades y actitudes conquistadas por los sujetos que participaron del proceso y apunta caminos hacia un fructífero diálogo entre cine y educación.

Palabras clave: lectura e interpretación. Cine. Práctica pedagógica.

\footnotetext{
*Doutora em Educação pela UFSM de Santa Maria-RS. Mestre em Educação pela UNISC de Santa Cruz do Sul-RS. E-mail: <juraskicamillo@gmail.com>.

**Doutora em educação pela Universidade Federal da Santa Catarina. Mestre em Educação pela Universidade Federal de Minas Gerais e graduada em Pedagogia pela Universidade Federal de Viçosa-MG. E-mail: <maria.viella@ifsc.edu.br>.
} 


\section{Palavras iniciais}

A escolha da palavra divertida-mente, separada por hífen, para compor o título deste artigo, foi proposital por ser portadora da ideia do lúdico, que de forma alguma exclui o trabalho intelectual, a mente. Por estar articulada pelo hífen, divertida-mente carrega consigo as possibilidades de que aprender supõe o lúdico, mas não se esgota nele. E, assim, o artigo vai tentando colocar no centro de suas reflexões o possível e frutífero diálogo entre o conhecimento científico e a ficção, sem perder de vista que tanto um quanto o outro "expressam a realidade, mas a expressam, a 'relatam', de modos profundamente diferenciados" (MORAES, apud MORAES e DUAYER, 1998, p. 70).

Este texto é resultado de uma pesquisa e de uma prática pedagógica realizadas com os alunos dos cursos técnicos em Fabricação Mecânica e Agroindústria, no ano letivo de 2015, no Instituto Federal de Ciência e Tecnologia de Santa Catarina, Campus Xanxerê, utilizando-se do cinema como ferramenta educativa. Partindo-se de observações do cotidiano das aulas de Comunicação e Expressão e Comunicação Técnica desses cursos, foi possível perceber algumas deficiências de leitura e interpretação dos mais variados textos que circulam na sociedade, por parte desse público de alunos. Buscando trabalhar essas dificuldades de uma forma diferenciada, surgiu a ideia do Projeto CineIFSC - Pipoca Educultural, que envolveu a exibição de cinco filmes: Jogada de gênio" (Flash of genius, com direção de Marc Abraham, 2009); Mary and Max, (com direção e roteiro de Adam Elliot, 2009); "Muito além do peso" (Way beyond weight, com direção de Estela Renner, 2012); "12 anos de escravidão" (12 years a slave, com direção de Steve McQueen, 2014); e "A vida é bela" ( $L a$ vita è bella, com direção de Roberto Benigni, 1997).

Para adentrar no campo da reflexão sobre o cinema como uma importante ferramenta e recurso de ensino na educação, optou-se por fazer um breve percurso pelos trabalhos apresentados na Anped. (Associação Nacional de Pós-Graduação e Pesquisa em Educação), no GT 24 "Educação e Arte". Também foi estabelecido um diálogo com outros autores que pesquisaram a temática, além daqueles autores dos trabalhos da Anped. Com isso, foi possível avaliar como essa discussão está posta e que caminhos podem ser trilhados na interface da educação com o cinema.

\section{O CINEMA NO GT 24 "EDUCAÇÃo E ARTE" E OUTROS CAMINHOS}

A escolha dos trabalhos da Anped se justifica pelo fato de ser esta a associação científica mais antiga e prestigiada em Educação, com objetivo de consolidar o ensino de pós-graduação e a pesquisa educacional no país. As reuniões anuais são consideradas, hoje, pela Coordenação de Aperfeiçoamento de Pessoal de Nível Superior (Capes), como eventos de "Qualis Internacional A" na área de Educação, portanto uma referência para acompanhamento da produção brasileira no campo educacional.

Nas trilhas da Anped, percebe-se que a entrada da arte no circuito da produção científica no Brasil é relativamente recente, já que a primeira reunião anual (RA) aconteceu em Fortaleza, em 1978, e o GT 24 "Educação e Arte" só veio a ser constituído a partir da 32 a RA, em 2009. Nesta reunião inicial foi ministrado um minicurso, por Rosa Maria Bueno Fischer (UFRGS) e Fabiana de Amorim Marcello (ULBRA), intitulado "Cinema e Educação: nos descaminhos de uma política da imagem, o encontro com a formação estética".

A preocupação das autoras é explorar a forma como "se dá a construção da imagem dos ditos outros" [...] os anormais, os incorrigíveis nos mais variados materiais audiovisuais, em especial no cinema", buscando, assim, enfatizar como certos materiais fílmicos "acabam por nos mobilizar eticamente no momento em que pensam diferentemente o outro por meio da linguagem-arte" (FISCHER; MARCELLO, 2009, p.2).

Dos 89 trabalhos apresentados de 2009 (ano da 32a RA e primeiro ano do GT 24 "Educação e Arte") a 2015, a temática do cinema aparece no título em apenas dois artigos - "Tartarugas podem voar: cinema, educação e infância", apresentado na 34aㅡ RA, em 2011, e "Cinema infantil, arte e indústria cultural”, apresentado na $36^{\mathrm{a}} \mathrm{RA}$, em 2013. Assim, esse percurso revela que ainda há muito a ser dito sobre cinema e educação, e o presente trabalho se propõe a auxiliar a preencher parte dessa lacuna.

Em "Tartarugas podem voar: cinema, educação e infância", Roure (2011, p. 1) traz interessantes contribuições utilizando como referência o pensamento psicanalítico sobre arte. Em relação à importância dada à arte pelo discurso pedagógico, ela aponta que esse discurso "tende a esvaziar as dimensões simbólica e real de tal experiência". A autora alerta para o cuidado que se deve ter em não subsumir a análise estilística da obra nos "procedimentos de natureza interpretativa onde se toma quase exclusivamente a decifragem dos signos". Para ampliar seu argumento, recorre a uma observação do crítico de cinema, Jean-Claude Bernadet, trazendo o seguinte: "Quase sempre, quando falamos de filmes, não é deles que falamos, e sim dos andaimes interpretativos que erguemos em volta deles". Nessa direção, vai apontando caminhos pouco trilhados nos usos do cinema na educação.

Ao narrar de forma muito densa e provocativa a experiência obtida com o filme citado, Roure (p.7) faz 
com que o leitor se enrede nas suas reflexões, mostrando de forma primorosa o que passa invisível no visível, bem como a experiência do indizível.

Ao analisar a primeira cena do filme, que mostra uma menina adolescente caminhando em direção a um penhasco para de lá finalmente "voar" o seu voo sem volta, sinaliza uma possibilidade, antes invisível, de articular arte, cinema e educação, afirmando o seguinte:

[...] ao reduzirmos uma sessão de cinema a discussões e processos interpretativos, contribuímos com a ilusão de uma significação totalizante e interditamos ao aluno a "experiência do estranhamento", ou seja, colocar em suspensão tudo o que até então pode ser significado para só então (ocupando a posição de testemunha) poder dizer uma outra coisa. E se isso é muito pouco, deixemos que a experiência com o impossível de dizer nos conduza... (ROURE, 2011, p. 13).

Um outro artigo localizado no GT da ANPEd "Cinema infantil, arte e indústria cultural”, vai "discutir as condições de produção e recepção dos bens culturais sob a regência do capitalismo" (SOUZA, 2013, p. 1), problematizando o cinema, mediado pelos conceitos de arte e indústria cultural. $\mathrm{O}$ autor destaca que "para ser educativa a arte precisa ser arte, e não arte educativa". (SOUZA, 2013, p. 6). Isto complementa as reflexões que são realizadas a seguir, no próximo tópico.

O cinema ganha um espaço especial na 37a RA, realizada em 2015, em Florianópolis, com a estreia da Mostra Curta ANPEd, que teve "por objetivo dar visibilidade a filmes que propiciam a reflexão sobre o uso das ferramentas e linguagens audiovisuais no processo de produção de pesquisas e conhecimentos", conforme consta na página de abertura do evento. Isto coloca no centro do debate que o espaço para as reflexões sobre o cinema no campo acadêmico-científico precisa ser ampliado e que formar também supõe passar pelas aparências para ir além delas.

\section{RAZÃO E IMAGINAÇÃO: A INTERFACE DA EDUCAÇÃO COM O CINEMA}

De acordo com Catelli (2005, p.4), as primeiras propostas de utilização do cinema com fins pedagógicos foram feitas já na década de 1920 e, na década seguinte, vários órgãos públicos manifestaram interesse nesse movimento. Desde as primeiras iniciativas de se utilizarem obras cinematográficas em sala de aula, esse uso ao longo do processo educativo ainda é visto muitas vezes como mero complemento desse processo ou mesmo não ganhou ainda o espaço merecido. Costa (1987, p. 39) explica que a introdução do cinema na escola (e, mais em geral, a presença da problemática relativa às linguagens audiovisuais) torna-se um momento de confronto entre um tipo de cultura centrado na palavra (aquela que, institucionalmente, a escola deve transmitir) e aquela que poderíamos chamar de cultura icônica (a imagem em todas as suas possíveis articulações e em suas integrações com a palavra), que tem, como vimos, uma parte cada vez mais importante nos processos informativos e 'formativos'.

O problema, portanto, não estaria no cinema em si, mas na lógica da educação, que privilegia o uso de determinado tipo de linguagem em detrimento de outros, o que leva o cinema a ocupar um papel secundário em um processo que poderia ser mais rico e diversificado caso ocorresse de forma diferente.

Quando se junta a experiência dos alunos com o cinema e com a atmosfera cultural em que vivem esses alunos, desenvolve-se uma "competência para ver", o que, para Pierre Bourdieu (1979, apud DUARTE, 2002, p. 13), viabilizaria a análise, a compreensão e a apreciação de narrativas cinematográficas. A partir do momento em que a aproximação dos alunos com o cinema se naturaliza, é possível que o professor possa trabalhar mais profundamente com o aluno o desenvolvimento dessa competência. Não é somente o aluno que sai ganhando quando são realizadas em sala de aula atividades que têm como elemento principal obras cinematográficas. Para Napolitano (2013, p. 11), "trabalhar com o cinema em sala de aula é ajudar a escola a reencontrar a cultura ao mesmo tempo cotidiana e elevada, pois o cinema é o campo no qual a estética, o lazer, a ideologia e os valores sociais mais amplos são sintetizados numa mesma obra de arte".

A busca por uma educação de qualidade suscita a utilização de metodologias e de objetos de ensino que provoquem nos alunos a reflexão acerca de temas que fazem parte de seu cotidiano. Nas palavras de Sacramento (2009, p. 7 e 8), caberia à escola a construção de uma "educação cinematográfica" propiciando, principalmente aos alunos, novas formas de ver e de interpretar o mundo.

$\mathrm{O}$ cinema e as artes em geral podem recriar e reinventar o real, oferecendo possibilidade de problematização do contexto econômico, histórico e cultural do qual eles fazem parte. As artes, em sua diversidade, têm se mantido sensíveis ao acontecer social. Como incorporá-las na formação de professores e alunos?

Dialogando com Lins (2014), é possível depreender que os discursos visuais, dentre eles, naturalmente, o cinema, estão circunscritos em práticas sociais e pretendem disciplina rizar o olhar (no sentido foucaultiano, como adverte a autora), orientando para o belo e para o feio, para o certo e para o errado, etc. E a escola, como uma instituição privilegiada no sentido de 
disseminar ideologias, participa ativamente da construção da cultura visual e da formação do sujeito visual. Assim, a intenção do projeto foi permitir alguns olhares sobre os filmes exibidos, porém que não excluíssem outros olhares e não se pretendessem verdades absolutas e irrefutáveis sobre os mesmos.

Esteve (apud Camillo, 2011), teorizando sobre os fatores que levam ao mal-estar docente, sustenta que, hodiernamente, o galopante desenvolvimento de fontes de informações alternativas à instituição escolar gera um desencantamento com a figura do professor e, por conseguinte, com a educação escolar como um todo. Como antídoto para essa problemática, o referido autor aconselha a integração do trabalho docente ao potencial educativo das tecnologias da informação e comunicação, o que abarca, dentre outras possibilidades, o uso do cinema como ferramenta educativa.

Definitivamente, vive-se o ápice da imagem, em suas múltiplas tipologias e dimensões. Segundo Cordeiro (2009), o cinema é, dentre outras artes que se ocupam da imagem, a que mais se aproxima da realidade, através de seu efeito especular sobre a mesma. Por essa razão, pode atingir uma gama diversa de públicos, desde letrados e não letrados, ou então as mais variadas faixas etárias, as quais significarão as narrativas fílmicas segundo suas concepções de mundos, ampliando-as significativamente.

Há duas maneiras imbricadas de se trabalhar com filmes na instituição escolar e que o presente projeto pretendeu contemplar. Uma, quando a sétima arte é usada no âmbito das disciplinas para se estudar conteúdo específicos. Outra, quando a intenção é ampliar a cultura geral dos destinatários da atividade (NAPOLITANO, 2003; SOUSA, 2005). As duas estão imbricadas, pois não há como focalizar uma, sem, também, obterem-se benefícios da outra.

Essas múltiplas possibilidades de se utilizar o cinema na educação são apenas algumas destas. Podem existir muitas outras, segundo a maneira pela qual os sujeitos as significam. Isso corrobora tanto para a aquisição de conhecimentos específicos nas cercanias de uma área do conhecimento ou disciplina como também para a aquisição da cultura historicamente acumulada, tomada holisticamente.

O que vale destacar neste momento também é o necessário cuidado que se deve ter para não didatizar ou escolarizar o objeto estético, transformando-o em objeto para ensino de qualquer disciplina. Negar o estético implica empobrecê-lo, desvirtuá-lo, desfigurá-lo.

Alguns autores que tratam dessa temática, embora dirigindo o foco da análise para a literatura, encaixam-se perfeitamente nas abordagens deste artigo, que pretende tratar dos usos do cinema na escola. Brayner (apud Viella, 2008, p. 181) afirma "que toda recuperação pedagogizante da obra literária não passa de uma forma de controle de sua recepção", isto é, "uma maneira de administrar a ficção". Todo cuidado é pouco. Nem pedagogizar o estético, nem esteticizar o pedagógico. Moraes e Duayer (referindo-se à história real e à literatura) também deixam contribuições sobre as necessárias distinções entre o contexto literário e o contexto histórico

[...] embora sejam ambos (contexto literário e o contexto histórico) processos de 'recriação' e 'invenção do real, o limite entre eles é claramente demarcado. Constituem-se em 'narrativas' de porte e competência diferentes: expressam a realidade, mas a expressam, a 'relatam', de modos profundamente diferenciados (MORAES, apud MORAES e DUAYER, 1998, p.70).

Mesmo em se tratando da literatura, é bom lembrar que tanto ela quanto o cinema, nesse caso, nosso objeto de estudo, são objetos estéticos. Não se trata de negar a importância da literatura e/ou do cinema para problematizar alguns aspectos do processo educativo e seus elementos constitutivos, mas deixar claro, conforme Moraes e Duayer (apud Viella,1998, p. 183), que "o texto literário e o contexto histórico não são uma mesma trama: um não pode ser reduzido ao outro nem tomados como idênticos".

Reforçando, com os argumentos dos autores, tanto o cinema quanto a literatura "engendram o sentido de realidade de uma cultura e das formações sociais sobre as quais ela intervém para sustentar, resistir ou contestar" (idem). Nessa direção, foi colocado em ação o projeto CineIFSC - Pipoca Educultural.

\section{ENTRANDO NO CINEMA PELA PORTA DA escola: o Projeto CineIfSC - Pipoca EDUCULTURAL}

Considerando todas essas reflexões, somadas a vivências e observações do cotidiano das aulas de Comunicação e Expressão e Comunicação Técnica no IFSC - Campus Xanxerê, com os alunos dos cursos técnicos em Fabricação Mecânica e Agroindústria, no ano letivo de 2015, surgiu o Projeto CineIFSC - Pipoca Educultural. Essas observações e vivências revelaram alguns problemas enfrentados pelos alunos, ao entrarem nessa instituição, relacionados a severas deficiências de leitura e interpretação dos mais variados textos que circulam na sociedade. Essas dificuldades emperram não apenas a caminhada escolar desses sujeitos, representada pelo seu itinerário formativo, mas, principalmente, sua capacidade de ler e interpretar o mundo em sentido amplo, como cidadãos.

Esse revés, em parte, no referido recorte espacial, ocorre em função de que, em sua grande maioria, esses 
alunos precisam adentrar no mercado de trabalho desde tenra idade, o que, de certa forma, priva-os de um tempo de contato mais efetivo com os artefatos culturais que favorecem essa habilidade leitora e crítica, como o acesso aos livros e aos filmes. Sem contar que, quanto aos últimos, em específico, tema central do projeto que originou este escrito, o município de Xanxerê oferece pouco ou nenhum ensejo de acesso, já que não dispõe de cinemas, tampouco de teatros, apenas de uma biblioteca pública bastante deficitária. Quanto a peças teatrais, em alguns ensejos acontecem algumas encenações por parte de grupos trazidos à cidade por iniciativa do Sesc-SC.

Diante disso, ciente do potencial cinema como recurso potencializador das interpretações de textos e de mundos, o projeto se propôs a fazer uma intervenção na problemática citada. Para tanto, disponibilizou aos alunos a oportunidade através de tempo/espaço institucional para assistir a um filme por mês, com o intuito de promover uma imersão mais significativa em várias temáticas que auxiliariam no sentido de ampliar suas visões de mundo.

Com isso, esperava impactar positivamente tanto a formação do aluno quanto a do cidadão - leia-se, portanto, a educação integral, que é, afinal, o objetivo maior da educação. Assim, a instituição estaria, de fato, cumprindo com seu papel social.

Tentando superar parte dessas dificuldades, foi colocado em prática o projeto CineIFSC - Pipoca Educultural, Campus Xanxerê. Resumidamente, o projeto possibilitou a exibição de filmes que serviram como base para que fossem realizadas discussões a respeito de temas diversos. Longe de utilizar o cinema como mero complemento, nesse projeto a obra cinematográfica foi pensada como protagonista, vindo ao encontro da ideia de Xavier (2008, p. 15), para quem

o cinema que 'educa' é o cinema que faz pensar, não só o cinema, mas as mais variadas experiências e questões que coloca em foco. Ou seja, a questão não é "passar conteúdos", mas provocar a reflexão, questionar o que, sendo um constructo que tem história, é tomado como natureza, dado inquestionável.

O presente projeto consistiu na exibição mensal de um filme, nacional ou estrangeiro, a todos os alunos e servidores do IFSC - Campus Xanxerê-SC, acompanhada de discussão através de questões elaboradas para reflexão após a projeção dos filmes.

As exibições - vespertinas e noturnas - tiveram lugar no auditório do campus e ocorreram no horário de aula, seguindo um cronograma que contemplou a apresentação dos filmes da seguinte forma: no primeiro mês, o filme foi exibido no primeiro horário da segunda-feira; no segundo mês, no primeiro horário da terça-feira; e, assim, sucessivamente, sendo que, no último mês de exibição, a mesma coincidiria com a sexta-feira. Dada a dinâmica do cotidiano, o cronograma sofreu algumas alterações, mas os cinco filmes foram exibidos e trabalhados, segundo o planejamento prévio efetuado.

Quanto à metodologia de gerenciamento do projeto, foram aplicados dois questionários semiestruturados aos discentes e servidores: um no início do projeto, com a finalidade de averiguar ideias e sentidos que o público-alvo atribuía ao projeto inicialmente; e um, ao final, objetivando avaliar o projeto, a saber, procurando auscultar, entre esses sujeitos, a validade da atividade, os aprendizados construídos, as sugestões e críticas para outras possíveis versões do mesmo.

A seguir, obedecendo à sequência temporal dos acontecimentos, tem-se no resultado do questionário inicial, aplicados aos discentes e servidores, um panorama das exibições de filmes e das discussões suscitadas e a avaliação do projeto por intermédio do questionário final aplicado ao público-alvo.

\section{UM OLHAR INICIAL PARA O PÚBLICO-ALVO}

Responderam ao questionário inicial, conforme dito, 81 discentes e nove servidores. Indagados, disseram que gostavam em parte ou não gostavam de assistir a filmes. Percebe-se que a maioria absoluta dos alunos (93\% na Agroindústria e 98\% na Fabricação Mecânica) gosta de filmes.

Em relação à frequência que os discentes assistiam a filmes, o instrumento revela que a maioria assiste frequentemente $(60 \%$ na Agroindústria, $69 \%$ na $\mathrm{Fa}$ bricação Mecânica e Mecânica), enquanto 33\% na Agroindústria e 31\% na Fabricação Mecânica e Mecânica assistem esporadicamente. Esses últimos dados não podem ser ignorados e justificam o projeto na instituição - assistem de forma esporádica, provavelmente, por falta de acesso ou de tempo para tal, já que manifestaram gostar de filmes.

As escolhas dos filmes surgiram espontaneamente dos estudantes e de seus entendimentos acerca de gêneros que mais simpatizavam. Vários foram apontados em ambos os cursos, alguns mais, outros menos: ação (44), comédia (34), aventura (13), romance (12), ficção (11), terror (10), suspense (4), drama (3), faroeste (2), histórico (1), mitológico (1), desenho (1), de época (1). E seis alunos/as manifestaram gostar de todos os gêneros de filmes.

Em relação ao gênero, cabe salientar, conforme Aumont apud Pinto (2016, p. 65), que 'todo filme é um filme de ficção'. 
não importa se a câmera esteja capturando imagens de uma cidade repleta de pessoas reais, sem o uso de personagens e efeitos, este material jamais será um retrato fiel da realidade. [...] A partir do momento que o dito real é capturado por uma câmera, o cineasta já fez escolhas de quais enquadramentos utilizar e, posteriormente, terá também que escolher a ordem das imagens na montagem, a trilha sonora, ou seja, a realidade é transformada e manipulada por meio dessas escolhas que envolvem a produção e edição de um filme. Até mesmo os "documentários de representação social" [...] preocupados, na maioria das vezes, em contar fatos verídicos - não são capazes de reproduzir com fidelidade o real, já que passam pelos mesmos processos de escolhas de seu realizador, como em qualquer outro filme.

Como o projeto objetivou contribuir na educação integral dos discentes por intermédio do cinema, com vistas a ampliar o acesso à cultura dos sujeitos, a quinta questão buscou saber se os discentes, no âmbito da sua educação formal via escola, consideravam importante utilizar filmes nas aulas. Nos cursos de Agroindústria (93\%) e de Fabricação Mecânica (88\%) e mecânica (82\%), os alunos mostraram a grande importância atribuída aos filmes utilizados em sala de aula. Alguns relativizaram essa importância (7\% na Agroindústria, $6 \%$ na Fabricação Mecânica e 14\% em Mecânica), e uma porcentagem mínima não viu importância no uso de filmes ( $6 \%$ na Fabricação Mecânica e 4\% em Mecânica).

Buscou-se também com o instrumento avaliar se os discentes tinham professores/as que usavam filmes em suas aulas. Como grande parte dos/as alunos/as são de matriz concomitante (Agroindústria e Mecânica), ou seja, fazem o ensino médio em outra escola e o curso técnico no IFSC, não há como saber se as respostas a essa pergunta diziam respeito apenas aos docentes do IFSC ou se abrangiam, também, os docentes do ensino médio. Em todo caso, as respostas apontam para o fato de que os filmes ainda são pouco explorados como recurso educativo, quer no âmbito do ensino médio cursado por esses sujeitos em outras escolas do município, quer especificamente em se tratando do IFSC.

Intentou-se, ainda, avaliar a forma como esses filmes eram trabalhados pelos professores. Algumas exibições eram feitas, e a partir delas eram solicitados trabalhos sobre os filmes. As exibições também eram usadas para introduzir questionamentos, fazer comparações entre os filmes e a realidade e/ou entre o passado e o futuro, para ilustrar temas trabalhados, como forma de motivação, para introduzir temas/assuntos, para informar, para suscitar debates, para fazer interpretações, para trabalhar conteúdos (bastante citado o uso de vídeos do telecurso, embora não sejam propriamente filmes), para distração nos momentos vagos, para trabalhar valores e para complementar conteúdos. Destaca-se que não foi citado o uso de filmes para problematizar, contextualizar e/ ou mobilizar o conhecimento, algo em que os mesmos poderiam prestar enorme contribuição à (re) construção de conhecimentos em sala de aula e, de modo amplo, à educação.

Cabe salientar, ainda, que, em relação ao pouco uso de filmes pelos docentes em suas aulas, quer do IFSC ou fora dele, há um longo caminho a percorrer, inclusive nas pesquisas, para que se verifique ou não a real viabilidade e potencialidade dos mesmos no processo educativo. Para isso, a ousadia é uma forte aliada.

A última questão feita aos discentes objetivou saber que temas gostariam que fossem contemplados pelos filmes exibidos no projeto, sendo que vários deles foram observados: ciência ( $1^{\mathrm{o}}$ e $3^{\mathrm{o}}$ filmes), história (4으 e $5^{\circ}$ filmes), racismo (4을 e $5^{\circ}$ filmes), cidadania (em todos os filmes), meio ambiente, alegria (de certa forma, em todos os filmes), sonhos, alegria, criatividade, superação, biografias, respeito, motivacional, distração, o ser diferente, educação, ética, política (de certa forma, em maior ou menor grau, em todos os filmes) e guerra (5을 filme).

O instrumento permitiu traçar um perfil dos discentes como um público que gosta de filmes, porém não os assiste com tanta frequência, seja por falta de tempo, seja pelo acesso um tanto dificultado aos mesmos, já que o município não possui cinemas; um público acredita que o uso de filmes atrelado à educação formal seja de valia, porém seus professores, por razões que desbordam deste estudo, ainda os utilizam de modo incipiente; um outro público aprecia diversos tipos de filmes e possui expectativas de ver diversos temas sendo contemplados nas exibições.

No tocante aos servidores, se, no momento da socialização do projeto, houve previamente total apoio a este nas reuniões de área, foram poucos os questionários retornados (apenas nove, de 27 servidores, sendo cinco docentes e quatro TAEs (Técnicos Administrativos).

A totalidade dos servidores revelou gostar de filmes, porém os assiste esporadicamente ou raramente, o que, mais uma vez, reforça a relevância do projeto enquanto tempo/espaço institucional para tal atividade. Quanto aos docentes em específico, todos afirmaram usar raramente ou nunca filmes em suas aulas, o que vai ao encontro das respostas dadas pelos discentes e das ponderações acima. Em suma, o padrão dos parcos retornos dos colegas servidores coincide com os retornos dos discentes, tanto no gosto por filmes como na frequência em que assistem e os utilizam em suas aulas (os/as docentes). Assim como também na expectativa dos temas abordados no projeto, com algumas sugestões que foram acatadas no decorrer do mesmo, como a de exibir o documentário "Muito além 
do peso", o qual, inicialmente, não constava na lista de exibições, mas foi considerado em função de que possuía relação direta com o curso de Agroindústria. E ainda porque abordava a questão da alimentação saudável, importante para todos e, curiosamente, tema ainda pouco tratado nos currículos escolares.

\section{As exibições fílmicas do Projeto CineIfSC - Pipoca Educultural}

A primeira exibição aconteceu no início do mês de agosto, no primeiro horário dos turnos vespertino e noturno, e foi um sucesso. Teve-se a participação da totalidade dos alunos dos cursos técnicos e do Pronatec/Mulheres Mil, do campus, totalizando mais de 150 pessoas. Degustando uma pipoca, assistiu-se ao filme "Jogada de gênio" (EUA, 2009, direção de Marc Abraham), baseado na história verídica do professor e inventor norte-americano Robert Kearns, o qual inventou o sistema de limpador de para-brisas intermitente. Este até hoje é utilizado na indústria automobilística, porém foi enganado pela Ford, tendo seu invento copiado e roubado. Obcecado pelo desejo de justiça, percorreu um longo caminho de lutas e sofrimento até conseguir chegar a um julgamento e ver a justiça acontecer.

Após a exibição, foram apresentadas aos participantes cinco questões, sobre as quais os/as participantes conversaram e debateram em pequenos grupos, posteriormente socializando as impressões que tiveram no grande grupo, sendo essa metodologia para o momento posterior às exibições adotada nas demais apresentações de filmes do projeto. Os/as alunos/as e também alguns docentes presentes destacaram questões como a ética (tanto em geral quanto na pesquisa), a persistência/ perseverança, a má-fé das grandes corporações em questões análogas à mostrada no filme, a ideia de que o dinheiro pode resolver tudo, a importância do apoio da família. Enfim, as discussões foram de alto nível, revelando-se como ingredientes fundamentais no processo de (ré)construção de conhecimentos.

O segundo filme exibido na vigência do projeto, no mês de setembro de 2015, foi "Mary and Max: uma amizade diferente" (animação australiana de 2009, dirigida por Adam Elliot), sendo que mais uma vez o auditório do campus ficou lotado pela presença de alunos/ as e servidores/as.

Análogo à primeira exibição, o filme suscitou diálogos e debates muito profícuos, permitindo trocas e (ré)significações, além do exercício de escuta das opiniões dos/das outros/as. Foram destacados temas como a síndrome de Asperger; o "ser diferente"; a importância da amizade, já que o ser humano é um ser social e precisa do/da outro/a; a homossexualidade, já que Mary adulta é abandonada pelo esposo que vai viver com um namorado; situações como solidão, depressão, alcoolismo, fobias, presentes no filme; as especificidades da comunicação humana, já que a amizade entre Mary, uma menina australiana de 8 anos, e Max, um norte-americano de 44 anos, iniciou-se através de uma carta enviada por Mary, ao pegar, aleatoriamente, o endereço de Max em um catálogo telefônico da América, atendendo ao seu enorme desejo de ter um amigo. O público também apontou o fato de a comunicação, em certos ensejos, aproximar Mary e Max; enquanto em outros, distanciava-os, porque as mensagens trocadas eram recebidas e significadas conforme o contexto e as características presentes na constituição de ambos. O que se apresenta como uma especificidade muito marcante da comunicação humana, pois se lê, escreve-se, interpreta-se a partir do que se é, levando-se em conta as experiências que se tem como humanos.

A questão da ética novamente sobreveio, numa associação com o primeiro filme exibido ("Jogada de gênio"), pois Mary, já adulta, em sua formação acadêmica, resolve estudar as doenças da mente e escolhe Max como seu estudo de caso, produzindo um material bastante elogiado pela comunidade acadêmica. Todavia, nesse aspecto, embora Mary tenha a melhor das intenções ajudar/"curar" o amigo - ele recebe muito mal a notícia, pois não desejava ser "curado", aceitando-se bem na "pele que vestia" como portador da síndrome de Asperger.

No final do filme, após muitos desencontros, Mary, finalmente, consegue ir para os EUA visitar o amigo. Contudo, era tarde demais, pois o mesmo havia falecido. Uma aluna do Pronatec/Mulheres Mil destacou que o final a ensinou a não protelar demais coisas que gostaria de fazer, sob pena de que, quando as fizer, talvez já seja tarde. E hoje, em um mundo guiado pelos apelos do capitalismo e pautado pela necessidade de trabalho constante e ininterrupto, as pessoas, muitas vezes, acabam deixando para depois coisas de muita significância, como visitar um amigo - caso de Mary - e quando o fazem já é tarde.

Os discentes também observaram a forma um pouco distinta pela qual o filme foi produzido e o enredo se desenrola, já que se trata de uma animação destinada a adultos. A narrativa também acontece de uma forma um pouco diferente do que os/as alunos/as disseram estar acostumados a assistir. O uso e o efeito das cores no filme - o marrom no universo de Mary e o cinza no de Max também foram percebidos e apontados pelos discentes, sendo que essas escolhas não são neutras por parte de autor e produtores de um filme. Isso porque, no caso específico de Mary e Max, tais cores estão fortemente associadas ao ambiente de solidão e depressão que envolvia ambos, onde as cores quentes e vibrantes estavam ausentes. Um 
aluno do Curso Técnico em Mecânica apontou isso como positivo - a oportunidade de assistir a filmes diferentes, sob outras perspectivas, que oportunizam olhar para o mundo e para tais temas de formas variadas. Isso revela o quão rico é o trabalho com filmes.

A terceira exibição de filmes do projeto abriu espaço para uma novidade, por sugestão feita por uma colega docente da área de Alimentos, em um dos questionários iniciais retornados, que foi a inclusão do documentário "Muito além do peso", produção nacional de 2012, que aborda a questão da obesidade no Brasil.

Temas como obesidade e problemas decorrentes, sedentarismo e excessiva propaganda com a qual as grandes corporações do ramo alimentício bombardeiam, sobretudo as crianças, foram alguns dos assuntos que vieram à tona no momento destinado para se discutir o filme/documentário. Além da dificuldade de alimentar-se bem e de fazer atividade física, haja vista que a organização da vida moderna não favorece tais práticas.

Todos e todas, de certa forma, estão implicadas com essas questões, já que elas se inserem em algo maior, que é a organização do/no modo de produção capitalista, o qual nem sempre privilegia a saúde em detrimento dos lucros exacerbados das grandes corporações.

No Dia da Consciência Negra, 20 de novembro, foi a vez da exibição do quarto filme do projeto, e o escolhido foi o vencedor do Oscar 2014, "12 anos de escravidão", que serviu de pretexto para o debate sobre a temática do racismo. Este conta a história real de Solomon Northup (autor do livro que deu origem ao filme), negro livre que foi sequestrado e vendido como escravo em 1841, sendo mantido na escravidão em fazendas dos Estados Unidos por 12 anos. A direção é de Steve McQueen, com Chiwetel Ejiofor, Michael Fassbender e Lupita Nyong'o, vencedora do Oscar de melhor atriz coadjuvante.

O filme gerou várias discussões e reflexões. Dentre estas, interrogou-se os/as presentes sobre a pertinência de se falar em racismo após decorridos 127 anos da abolição da escravatura pela Lei Áurea no Brasil, em relação ao que se avançou sobre a questão e ao que ainda precisa se avançar.

A questão do racismo foi logo associada, na conversa, com a lei das cotas, sendo que foram manifestados, sobre o tema, posicionamentos diversos. De um lado, pessoas que defenderam a mesma como um ensejo de se reparar o mal feito no passado, trazendo esses sujeitos a uma condição de equiparação, no intuito de se haver, de fato, igualdade de acesso às oportunidades na sociedade em seus vários âmbitos. De outro lado, um grupo posicionouse contrário à lei das cotas, não reconhecendo a dívida/ necessidade histórica de se elevar esses sujeitos a uma situação de real igualdade de condições.
Ainda há muito que se avançar sobre a compreensão e o entendimento da temática das cotas, bem como sobre o respeito a outros grupos historicamente marginalizados como os índios, as mulheres, as pessoas com deficiência e, além disso, oferecer ensejos de acesso ao conhecimento historicamente produzido e à ciência, à participação, à autonomia, à emancipação e à humanização a TODOS e TODAS.

Não reconhecer e não aceitar essa prerrogativa se aproxima de uma das ideias de Paulo Freire (2007) quando alude que o oprimido, em diversas ocasiões, acaba se identificando com o opressor e passa a internalizar e a difundir posturas, ideias e posicionamentos do opressor, o que termina por perpetuar a opressão e a alienação. Isso porque esses sujeitos, embora oprimidos, não reconhecem sua posição enquanto tal, em consequência, não lutam para sair dela e ainda segregam outros sujeitos em igual posição. Ou, ainda, não reconhecer e não se sensibilizar com as demandas específicas desses grupos significa que é mister avançar e evoluir nesse tema; e que ainda precisa se falar, discutir-se, refletirse sobre tais assuntos e que uma instituição de educação pública que visa à formação integral necessita, sim, fazê-lo. E o CineIFSC foi um espaço privilegiado para tal.

Para a quinta e última exibição de filmes do projeto, o escolhido foi "A vida é bela", uma produção italiana de 1997, do gênero comédia dramática, dirigido e protagonizado por Roberto Benigni. O filme foi vencedor de três prêmios Oscar: melhor filme estrangeiro, melhor ator protagonista e melhor trilha sonora.

Após assistir ao filme, discutiram-se algumas temáticas, como a questão do holocausto e a construção, pelo personagem principal, de uma outra realidade diferente daquela que enfrentou juntamente com sua família, ao ser enviado para um campo de concentração, no afã de proteger seu filho da violência e das atrocidades da guerra. Apesar da situação adversa, Guido opta pela ludicidade e pelo otimismo para construir essa outra realidade para seu filho Giosué, resguardando-o de sofrer ainda mais.

Outra discussão deu-se na direção das analogias entre o filme "12 anos de escravidão", visto no mês de novembro, e o filme em questão. Ambos retratam casos de escravidão, discriminação e preconceitos, envolvendo grupos historicamente marginalizados, como os negros e os judeus, sendo que o holocausto, é oportuno lembrar, foi um episódio extremamente recente na história da humanidade.

$\mathrm{Na}$ esteira disso, nosso compromisso/desafio, enquanto pessoas de uma forma ou de outra envolvidas com a educação no âmbito institucional dos IFs, particularmente dos IFSCs - seja docente, TAEs ou 
discentes -, é, relembrando Theodor W. Adorno (2000), optar por um projeto de educação contra a barbárie, na qual eventos horrendos como os vistos e discutidos nos dois filmes jamais se repitam. Uma educação voltada a romper os ditames de uma sociedade onde ainda a cor de pele, a opção sexual e a posição econômica sejam categorias privilegiadas para escalonar pessoas. E, como bem sintetiza Lopes (2013, p. 8), “aprender a ver cinema é realizar esse rito de passagem do espectador passivo para o espectador crítico", essa "educação cinematográfica" sinaliza que uma formação integral passa também pela estética, na perspectiva de que o acesso fácil às imagens não dispensa o difícil trabalho intelectual e o constante movimento do pensamento para entender as sutis formas de representação do real.

\section{Palavras finais}

É possível asseverar que o Projeto CineIFSC Pipoca Educultural, na perspectiva da divertida-mente, alcançou os objetivos aos quais se propôs - a saber, possibilitar múltiplas leituras de mundos de forma lúdica ao seu público-alvo, alunos/as e servidores/as do IFSC Campus Xanxerê. Na interlocução feita com os trabalhos da ANPEd sobre a temática, evidenciou-se que esta é pouco explorada, o que deveras justifica a relevância do trabalho realizado e se coaduna com Flick (2009), ao aconselhar que, ao se encetar uma pesquisa científica, é indispensável consultar a literatura teórica, empírica e metodológica sobre o tema, no afã de localizar em que pontos o trabalho poderá trazer contribuições. Destaca-se também a acurada observação de Roure (2011) quanto ao que passa invisível no visível, bem como a experiência do indizível. Nesse sentido, reafirma-se a importância de se aliar cinema e educação, aqui mais particularmente o público da EPT, quando o intuito maior é se tecer uma educação de fato integral, que se ocupe de afetar, quiçá (trans)formar, corações e mentes. Foi o que ocorreu com os sujeitos que vivenciaram a experiência de participar das exibições de filmes e discussões as quais tiveram o presente projeto como tempo/espaço privilegiado.

A experiência também muito ensinou em direção ao cuidado de se trabalhar com filmes, de acordo com o teorizado a partir de Lins (2014), acerca da acuidade para com a domesticação do olhar, permitindo que de fato as práticas com o cinema possam inserir-se em uma pedagogia aberta, que não privilegie olhares, mas que considere todos os olhares possíveis sobre os negócios mundanos. Ousa-se declarar aberto o caminho do artistar no que tange ao binômio cinema-educação, percurso que não pode aceitar hierarquias, mas considera válida a coragem de se olhar.

\section{REFERÊNCIAS}

ADORNO, T. W. Educação e emancipação. 2. ed. São Paulo: Paz e Terra, 2000.

CAMILLO, E. J. Ócio e trabalho docente: um estudo em Sobradinho-RS e municípios circunvizinhos. Santa Cruz do Sul: Edunisc, 2013.

CATELLI, R. E. Aprender a ver: a irradiação da educação e da cultura, entre os anos de 1920 e 1940. In: ENCONTRO NACIONAL DE ESTUDOS MULTIDISCIPLINARES EM CULTURA - ENECULT, I., 2005, Salvador. Disponível em: <www.cult.ufba.br/enecul2005/RosanaElisaCatelli.pdf>. Acesso em: 12 jan. 2015.

CORDEIRO, P. A definição do sujeito no cinema - os dias estranhos do cinema ou a inconstância do eu e do outro nas personagens e no encontro entre o mundo real e a ficção. Disponível em: <http://www.bocc.ubi.pt>. Acesso em: 15 maio 2015.

COSTA, A. Compreender o cinema. Rio de Janeiro: Globo, 1987.

DUARTE, R. Cinema \& Educação. Belo Horizonte: Autêntica, 2002.

FISCHER, R. M. B.; MARCELLO, F. deA. Cinema e Educação: nos descaminhos de uma política da imagem, o encontro com a formação estética. Disponível em: < http://32reuniao.anped.org. br/arquivos/minicursos/32\%20ra $\% 20-\% 20$ minicurso $\% 20-\% 20$ gt24.pdf >. Acesso em: 15 maio 2016.

FREIRE, P. Pedagogia da autonomia: saberes necessários à prática educativa. 35. ed. São Paulo: Paz e Terra, 2007.

LINS, H. A. de M. Cultura visual e pedagogia da imagem: recuos e avanços nas práticas escolares. Educação em Revista. Belo Horizonte, v. 30, n. 1, p. 245-260, mar. 2014.

LOPES, J. S. M. Cinema e educação: o diálogo de duas artes. Revista SCIAS Arte/Educação, v. 1. n. 1, 2013, p. 2-14. 2013.

MORAES, M. C. M. de; DUAYER, M. História, estórias: morte do "real" ou derrota do pensamento? Perspectiva, Florianópolis, v. 26, n. 29, p. 63-74, jan.-jun. 1998.

NAPOLITANO, M. Como usar o cinema na sala de aula. 5. ed., 1aㅡ reimpressão. São Paulo: Contexto, 2013.

PINTO, Vinicius Soares. Zelig: o olhar de Woody Allen sobre o espetáculo pós-moderno. Temática, ano XII, n. 6, p. 62-76, jun. 2016. Namid/UFPB. Disponível em: <http://periodicos.ufpb. br/index.php/tematica/article/viewFile/29172/15584>. Acesso em: 23 mar. 2017.

ROURE, G. Q. de. Tartarugas podem voar: cinema, educação e infância. Disponível em: <http://34reuniao.anped. org.br/images/trabalhos/GT24/GT24-1074\%20int.pdf $>$. Acesso em: 21 jul. 2016.

SACRAMENTO, A. J. C. O cinema na prática pedagógica: Projeto Cine Modelo, realizado no Colégio Modelo Luiz Eduardo Magalhães. Juazeiro: Universidade do Estado da Bahia, 2009.

SOUSA, B. J. de. O cinema na escola: aspectos pedagógicos do texto cinematográfico. Dissertação (Mestrado) - Universidade Católica de Goiás. Disponível em: <http://www.bdtd.ibict.br/ vufind/Record/PGOI_25719213e2a54ea0fb50eeac163dbf84>. Acesso em: 20 maio 2015. 
SOUZA, André Barcellos Carlos de. Cinema infantil, arte e indústria cultural. Disponível em: <http://www.36reuniao. anped.org.br/pdfs_trabalhos_aprovados/gt24_trabalhos_pdfs/ gt24_2702_texto.pdf>. Acesso em: 15 maio 2016 .

VIELLA, M. dos A. L. Fetichismo da infância e do trabalho nos mapas do trabalho infantil. $268 \mathrm{f}$. Tese (Doutorado em Educação) - Programa de Pós-Graduação em Educação, Universidade Federal de Santa Catarina, Florianópolis, 2008.

XAVIER, I. Um cinema que "educa" é um cinema que (nos) faz pensar. Entrevista com Ismail Xavier. Educação \& Realidade, Universidade Federal do Rio Grande do Sul Porto Alegre. v. 33, n. 1, p. 13-20, jan.-jun. 2008. Disponível em: <http:// www.infoescola.com/cinema/historia-do-cinema/>. Acesso em: 25 out. 2015 .

\section{Filmografia}

A VIDA É BELA. Direção: Roberto Benigni. Produção: Vittorio Cecchi Gori. Local: Itália. Produtora: Estúdio Melampo Cinematográfica, 1997. 1h57min. Música: Nicola Piovani. Direção de fotografia: Torino Delli Colli. Gênero: Comédia Dramática.
12 ANOS DE ESCRAVIDÃO. Direção: Steve McQueen. Produção: Steve McQueen, Brad Pitt, Dede Gardner, Jeremy Kleiner, Bill Pohlad, Arnon Milchan e Anthony Katagas. Roteiro: John Ridley. Música: Hans Zimmer. Estados Unidos. Distribuição: Fox Searchlight Pictures, Entertainment One, Buena Vista International, 2014. 2h13min. Gênero: Biografia, Drama, Histórico.

JOGADA DE GÊNIO. Autor: John Seabrook. Direção: Marc Abraham. Produtor: Gary Barber. Roteiro: Philip Railsback. 2009, Estados Unidos. Universal Pictures, 2009. 120min. Gênero: Drama.

MARY E MAX: uma amizade diferente. Direção e roteiro: Adam Elliot. Produção: Matk Gooder, Paul Hardart, Tom Hardart, Bryce Menzies, Jonathan Page. Música: Dale Cornelius, 2009, Austrália, Gaumont, 2009. 92min. Gênero: Animação.

MUITO ALÉM DO PESO. Direção: Estela Renner. Produtor: Marcos Nisti, Juliana Borges. Fotografia: Renata Ursaia. Montagem: Jordana Berg. Música: Jukebox. 2012, Brasil. Produção: Maria Farinha Filmes. 2012. 84min. Gênero: Documentário.

Recebido em 22-12-2016. Aprovado em 17-05-2017. 